\title{
Place Cells, Grid Cells, and Memory
}

\author{
May-Britt Moser, David C. Rowland, and Edvard I. Moser \\ Centre for Neural Computation, Kavli Institute for Systems Neuroscience, Norwegian University of Science \\ and Technology, 7489 Trondheim, Norway \\ Correspondence: edvard.moser@ntnu.no
}

The hippocampal system is critical for storage and retrieval of declarative memories, including memories for locations and events that take place at those locations. Spatial memories place high demands on capacity. Memories must be distinct to be recalled without interference and encoding must be fast. Recent studies have indicated that hippocampal networks allow for fast storage of large quantities of uncorrelated spatial information. The aim of the this article is to review and discuss some of this work, taking as a starting point the discovery of multiple functionally specialized cell types of the hippocampal-entorhinal circuit, such as place, grid, and border cells. We will show that grid cells provide the hippocampus with a metric, as well as a putative mechanism for decorrelation of representations, that the formation of environment-specific place maps depends on mechanisms for long-term plasticity in the hippocampus, and that long-term spatiotemporal memory storage may depend on offline consolidation processes related to sharp-wave ripple activity in the hippocampus. The multitude of representations generated through interactions between a variety of functionally specialized cell types in the entorhinal-hippocampal circuit may be at the heart of the mechanism for declarative memory formation.

$\mathrm{T}^{\mathrm{h}}$ he scientific study of human memory started with Herman Ebbinghaus, who initiated the quantitative investigation of associative memory processes as they take place (Ebbinghaus 1885). Ebbinghaus described the conditions that influence memory formation and he determined several basic principles of encoding and recall, such as the law of frequency and the effect of time on forgetting. With Ebbinghaus, higher mental functions were brought to the laboratory. In parallel with the human learning tradition that Ebbinghaus started, a new generation of experimental psychologists described the laws of associative learning in animals. With behaviorists like Pavlov, Watson, Hull, Skinner, and
Tolman, a rigorous program for identifying the laws of animal learning was initiated. By the middle of the 20th century, a language for associative learning processes had been developed, and many of the fundamental relationships between environment and behavior had been described. What was completely missing, though, was an understanding of the neural activity underlying the formation of the memory. The behaviorists had deliberately shied away from physiological explanations because of the intangible nature of neural activity at that time.

Then the climate began to change. Karl Lashley had shown that lesions in the cerebral cortex had predictable effects on behavior in

Editors: Eric R. Kandel, Yadin Dudai, and Mark R. Mayford

Additional Perspectives on Learning and Memory available at www.cshperspectives.org

Copyright (C) 2015 Cold Spring Harbor Laboratory Press; all rights reserved; doi: 10.1101/cshperspect.a021808

Cite this article as Cold Spring Harb Perspect Biol 2015;7:a021808 
M.-B. Moser et al.

animals (Lashley 1929, 1950), and Donald Hebb introduced concepts and ideas to account for complex brain functions at the neural circuit level, many of which have retained a place in modern neuroscience (Hebb 1949). Both Lashley and Hebb searched for the engram, but they found no specific locus for it. A significant turning point was reached when Scoville and Milner (1957) reported severe loss of memory in an epileptic patient, patient H.M., after bilateral surgical removal of the hippocampal formation and the surrounding medial temporal lobe areas. "After operation this young man could no longer recognize the hospital staff nor find his way to the bathroom, and he seemed to recall nothing of the day-to-day events of his hospital life." This tragic misfortune inspired decades of research on the function of the hippocampus in memory. H.M.'s memory impairment could be reproduced in memory tasks in animals and studies of H.M., as well as laboratory animals, pointed to a critical role for the hippocampus in declarative memory-memory, which, in humans, can be consciously recalled and declared, such as memories of experiences and facts (Milner et al. 1968; Mishkin 1978; Cohen and Squire 1980; Squire 1992; Corkin 2002). What was missing from these early studies, however, was a way to address the neuronal mechanisms that led information to be stored as memory.

The aim of this article is to show how studies of hippocampal neuronal activity during the past few decades have brought us to a point at which a mechanistic basis of memory formation is beginning to surface. An early landmark in this series of investigations was the discovery of place cells, cells that fire selectively at one or few locations in the environment. At first, these cells seemed to be part of the animal's instantaneous representation of location, independent of memory, but gradually, over the course of several decades, it has become clear that place cells express current as well as past and future locations. In many ways, place cells can be used as readouts of the memories that are stored in the hippocampus. More recent work has also shown that place cells are part of a wider network of spatially modulated neurons, including grid, border, and head direction cells, each with distinct roles in the representation of space and spatial memory. In this article, we shall discuss potential mechanisms by which these cell types, particularly place and grid cells, in conjunction with synaptic plasticity, may form the basis of a mammalian system for fast high-capacity declarative memory.

\section{PLACE CELLS, SYNAPTIC PLASTICITY, AND MEMORY}

The growing interest in hippocampal function and memory led John O'Keefe and John Dostrovsky (O'Keefe and Dostrovsky 1971) and Jim Ranck (Ranck 1973) to introduce methods for recording activity from hippocampal neurons in awake and freely moving animals. Using miniaturized electrodes for extracellular single-cell recording, they were able to show reliable links between neural activity and behavior. The most striking relationship was noted by O'Keefe and Dostrovsky, who found that hippocampal cells responded specifically to the current location of the animal. They called these cells "place cells" (Fig. 1). Different place cells were found to have different firing locations, or place fields (O'Keefe 1976). Place was mapped nontopographically in the sense that place fields of neighboring cells were no more similar than those of cells that were far apart (O'Keefe 1976; Wilson and McNaughton 1993), although the size of the firing fields increased from dorsal to ventral hippocampus (Jung et al. 1994; Kjelstrup et al. 2008). The combination of cells that were active at each location in the environment was unique, despite the lack of location topography, leading O'Keefe and Nadel (1978) to suggest that the hippocampus is the locus of the brain's internal map of the spatial environment, a manifestation of the cognitive map proposed from purely behavioral experiments by Edward Tolman several decades earlier (Tolman 1948).

The discovery of place cells changed the way many experimental neuroscientists thought about hippocampal functions. Clinical studies starting with patient H.M. pointed to a role for the hippocampus in declarative memory (Squire 1992), but the fact that hippocampal 

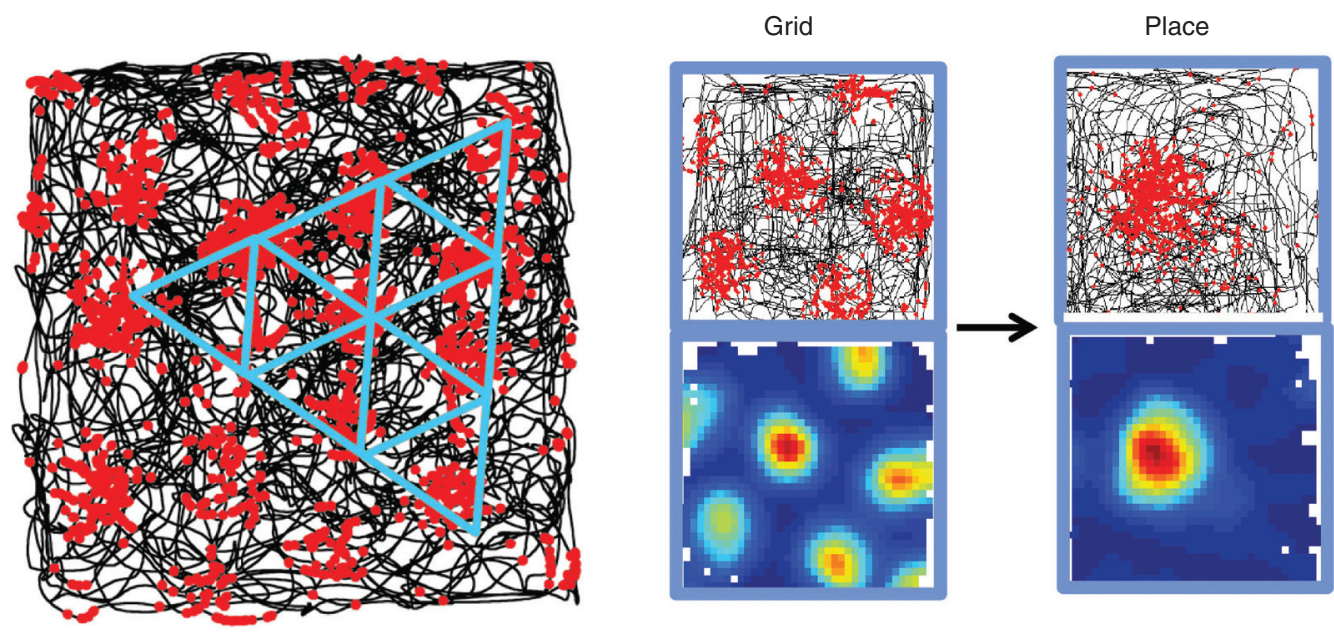

Figure 1. Grid cells and place cells. (Left) A grid cell from the entorhinal cortex of the rat brain. The black trace shows the trajectory of a foraging rat in part of a 1.5-m-diameter-wide square enclosure. Spike locations of the grid cell are superimposed in red on the trajectory. Each red dot corresponds to one spike. Blue equilateral triangles have been drawn on top of the spike distribution to illustrate the regular hexagonal structure of the grid pattern. (Right) Grid cell and place cell. (Top) Trajectory with spike locations, as in the left part. (Bottom) Colorcoded rate map with red showing high activity and blue showing low activity. Grid cells are thought to provide much, but not all, of the entorhinal spatial input to place cells.

neurons were so strongly modulated by location suggested that space was primary. Moreover, for the most part, place cells represented current space, not as expected if the function of the hippocampus was purely mnemonic. Reconciling space and memory functions remained a challenge for several decades after the discovery of place cells.

A framework that accounts for both lines of observation has now emerged. Converging evidence has suggested that hippocampal neurons respond also to nonspatial features of the environment, such as odors (Eichenbaum et al. 1987; Wood et al. 1999; Igarashi et al. 2014), tactile inputs (Young et al. 1994), and timing (Hampson et al. 1993). The same cells that respond to nonspatial stimuli fire like place cells when animals move around in space, suggesting that place cells express the location of the animal in combination with information about events that take place or took place there (Leutgeb et al. 2005b; Moser et al. 2008). The representation of space does not exclude a central role of the hippocampus in declarative memory, as space is a central element of all episodic and many semantic memories (Buzsáki and Moser 2013).

A role for place cells in hippocampal memory was apparent already in the earliest studies of place cells. It was shown in these studies that ensembles of place cells represent not only the animal's current location but also locations that the animal had visited earlier. In maze tasks, place cells fired when the animal made errors, as if the animal was in the location where the cell fired normally (O'Keefe and Speakman 1987). In spatial alternation tasks, firing patterns reflected locations that the animal came from, as well as upcoming locations (Frank et al. 2000; Woods et al. 2000; Ferbinteanu and Shapiro 2003), and during sequential testing in multiple environments, place-cell activity was found to carry over from one environment to the next (Leutgeb et al. 2004, 2005a). Moreover, sequences of spatial firing during exploration were shown to be replayed during rest or sleep subsequent to the behavioral experience, as if those patterns were stored in the hippocampal network during exploration and retrieved later in offline mode, when the animal was not acquir- 
M.-B. Moser et al.

ing new information (Pavlides and Winson 1989; Wilson and McNaughton 1994; Foster and Wilson 2006; O'Neill et al. 2006).

The fact that place cells express past experience raises the question whether ensembles of place cells are completely formed by experience or if there is an underlying component that is hardwired in the circuit. Hill (1978) sought to address this issue by recording place fields as rats entered a novel environment. Of the 12 cells that he recorded, 10 appeared to have spatial firing fields immediately, supporting the idea that the place-cell map was largely predetermined. Subsequently, studies with larger ensembles of cells found that place fields often took several minutes of exploration before settling into a stable firing field (McNaughton and Wilson 1993; Frank et al. 2004) and the formation of new and stable place fields was dependent on the animal's behavior and attention to the spatial features of the environment (Kentros et al. 2004; Monaco et al. 2014). These results point to a critical role for experience in forming the hippocampal map of space. However, the plasticity can occur extremely rapidly (Leutgeb et al. 2006) and, just as Hill observed, some place cells show stable firing fields immediately (Frank et al. 2004). Thus, place maps are expressed, in some form, from the very moment when animals are put into an environment for the first time, although the map may evolve further with experience. The findings raise the possibility that a skeletal map of a novel environment is drawn from a set of preexisting maps, and then gets modified to fit the specifics of the environment through experience-dependent plasticity (Samsonovich and McNaughton 1997; Dragoi and Tonegawa 2011, 2013).

The role of synaptic plasticity in the formation of place maps has been tested experimentally. In agreement with the proposed existence of prewired maps, neither systemic pharmacological blockade of $N$-methyl-D-aspartate (NMDA) receptors, nor subfield-specific targeted knockouts of such receptors, have a large effect on the basic firing patterns of place cells in familiar or novel environments (McHugh et al. 1996; Kentros et al. 1998), suggesting that place-field expression is quite inde- pendent of at least one major form of long-term synaptic plasticity. However, cellular mechanisms involved in long-term plasticity are clearly required for the long-term stability of newly formed maps (Rotenberg et al. 1996; Kentros et al. 1998). These studies suggest that the place-cell map of the environment is stored and stabilized through changes in synaptic weights, similar to other memory systems (Kandel and Schwartz 1982).

NMDA receptors also play a role in more subtle forms of experience-dependent modifications of place fields. One example is the experience-dependent asymmetric expansion of place fields observed following repeated traversals of place fields on a linear track (Mehta et al. 1997, 2000). It was suggested in theoretical studies in the 1990s that as a rat moves through locations $\mathrm{A}, \mathrm{B}$, and $\mathrm{C}$ along a linear track, the cells coding for location A will repeatedly activate the cells coding for location $\mathrm{B}$ and the cells coding for location B will, in turn, activate cells coding for location C. By the logic of Hebbian plasticity, the connections from A to B and B to $\mathrm{C}$ should become strengthened, with the result that place fields of cells $\mathrm{A}, \mathrm{B}$, and $\mathrm{C}$ are shifted forward on the track, against the direction of motion (Abbott and Blum 1996; Blum and Abbott 1996). Experimental evidence for such experience-dependent asymmetric expansion was obtained by Mehta and colleagues (1997, 2000). Subsequently, studies found that the asymmetric shift depends on NMDA receptor activation (Ekstrom et al. 2001), consistent with the suggestion that place maps are refined by experience-dependent long-term synaptic plasticity.

\section{MEMORY ENCODING}

What are the factors that determine whether new place maps are stabilized? One of the hallmarks of episodic memories is that attended information is more likely to be encoded and stored long term (Chun and Turk-Browne 2007). It is simply impossible to remember everything, and as Ebbinghaus's curve of memory shows, most memories will fade over time. However, some particularly meaningful mem- 
Place Cells, Grid Cells, and Memory

ories become permanent. On this background, Kentros et al. (2004) considered whether attention to spatial cues could improve the long-term stability of place fields. They trained mice to find an unmarked goal location in a cylinder (similar to the Morris water maze) while recording hippocampal place cells. The mice that learned the task had more stable place fields than mice that were simply running in the same cylinder with no task requirements. To test whether the driving force was true selective attention, as opposed to general arousal, Muzzio et al. (2009) trained mice to attend to odor cues and ignore spatial cues or vice versa. When the odors were the relevant cues, the hippocampal neurons acquired stable odor representations, but had less stable spatial representations. The reverse was true when space was relevant. Taken together with recent evidence suggesting that place fields can be induced by attentive scanning (Monaco et al. 2014), the findings point to selective attention, and not merely general arousal, as a major determinant of experiencedependent stabilization of hippocampal place maps.

What could be the mechanisms for selective attention in the hippocampus? Recently, Igarashi et al. (2014) recorded simultaneously from the lateral entorhinal cortex and CA1 region of the rat hippocampus as the animals learned an odor-place association. As the animals learned the association, the two structures showed an increasing degree of synchronous oscillatory activity in the 20- to $40-\mathrm{Hz}$ range and a corresponding increase in spiking activity to the rewarded odors. The development of temporal coherence between activity in the hippocampus and entorhinal cortex may allow CA1 cells to respond to particular entorhinal inputs at the same time as the cells are closest to firing threshold (Singer 1993). The 20- to $40-\mathrm{Hz}$ oscillation is substantially lower than the fast $(60-100 \mathrm{~Hz})$ gamma oscillation found in the medial entorhinal cortex (Colgin et al. 2009). The two subdivisions of the entorhinal cortex may, therefore, convey relevant information to the hippocampus via distinct frequency channels, each leading to a different firing pattern in the hippocampus.

\section{MEMORY CONSOLIDATION AND RETRIEVAL}

Once encoded, the memories must be consolidated. In an early theoretical paper, Buzsáki (1989) proposed that hippocampal memory formation occurs in two stages. First, there is a stage in which memory is encoded via weak synaptic potentiation in the CA3 network when the network is in theta-oscillation mode during exploratory behavior. Then, there is a memory consolidation stage, which can take place hours later during sharp-wave activity, associated with sleep and resting. In this stage, synapses that were weakly potentiated during the preceding exploration participate in sharp-wave activity that, in turn, evokes ripple activity in the CA1 area of the hippocampus. Ripples occur at a frequency that is optimal for induction of long-term potentiation (LTP) in efferent synapses of CA1 cells, possibly including long-distance targets in the cortex. By this mechanism, memory was thought to be slowly induced in the neocortex, consistent with a large body of evidence pointing to gradual recruitment of neocortical memory circuits in long-term storage of hippocampal memories (McClelland et al. 1995; Squire and Alvarez 1995; Frankland et al. 2001). Over the years, considerable evidence has accumulated to point to a role for sharp waves and ripples in the formation of hippocampus-dependent long-term memories. Selectively disrupting sharp-wave ripple activity during posttraining rest periods impairs learning, providing a causal link between sharp-wave ripples and consolidation (Girardeau et al. 2009; Ego-Stengel and Wilson 2010). Moreover, it is now clear that sequences of firing among place cells are replayed during subsequent sharp-wave ripples in the same or reverse order that the cells were active during experience (Wilson and McNaughton 1994; Foster and Wilson 2006; Diba and Buzsáki 2007). Structured replay is seen across many brain regions (Hoffman and McNaughton 2002), indicating that the sequence information from the hippocampus may be conferred on downstream cortical targets.

Recent work points to a wider role for replay in which replay may contribute not only to con- 
M.-B. Moser et al.

solidation and recall of memory, but also to planning of future behavior. Studies in human subjects show that overlapping hippocampal networks are activated during episodic recall and imagination of fictitious experiences (Hassabis et al. 2007). In animals, sharp-wave ripples can activate cells along both past and future trajectories (Karlsson and Frank 2009; Gupta et al. 2010; Pfeiffer and Foster 2013). Pfeiffer and Foster (2013), for example, trained rats to find a rewarded well within a large environment while sharp-wave ripple-associated replay events were recorded in the hippocampus. In many of the events, the sequence of active cells began at the current location and ended at the goal location, followed by the animal taking the path defined by the place-cell activity. Although the sequence of activated cells clearly preceded behavior, the phenomenon also depended on previous experience with the environment and the rules of the task. Thus, the replay can either lead or follow the behavior once the map of space is established. In that sense, the replay phenomenon may support "mental time travel" (Suddendorf and Corballis 2007) through the spatial map, both forward and backward in time. Whether the sharp-wave ripple-mediated replay in rats represents conscious recall is impossible to know, but observations in humans during free recall provide a clue (Gelbard-Sagiv et al. 2008; Miller et al. 2013). Miller et al. (2013), for example, recorded from the medial temporal lobe of human subjects as they navigated a virtual town (the subjects were awaiting surgery for epilepsy and had electrodes placed in their medial temporal lobe to localize the origin of the seizures, affording Miller et al. the rare opportunity to record place cells in humans). After an initial familiarization period, subjects were asked to deliver items to one of the stores in the town and when all the deliveries were complete, the subjects were asked to recall only the items they delivered. Remarkably, the place cells responsive to the area where the item was delivered became active during recall of the item, closely mirroring the reactivation of place cells during replay events in rodents. Although free recall in humans is not likely to correspond to sharp-wave ripple events (Watrous et al. 2013), the time course of reactivation was similar to a typical sharp-wave ripple event in rodents, and may therefore reflect a qualitatively similar phenomenon. The place cell activity during recall of events or items likely brings to mind the spatial context in which the events and items were experienced, creating a fully reconstructed memory for what was experienced, along with where it was experienced.

\section{UPSTREAM OF PLACE CELLS: GRID CELLS AND OTHER CELL TYPES}

To get a better insight into the mechanisms of memory formation in hippocampal place-cell circuits, it may pay off to consider how place cells interact with cells in adjacent brain systems. The origin of the place-cell signal was long thought to be intrahippocampal, considering that early recordings upstream in the entorhinal cortex showed only weak spatial modulation (Barnes et al. 1990; Quirk et al. 1992; Frank et al. 2000). At the turn of the millennium, we started a series of experiments aimed at localizing the sources of the place signal. First, we isolated the CA1 region of the hippocampus from the earlier parts of the hippocampal excitatory circuit, that is, the dentate gyrus and the CA3 (Brun et al. 2002). Activity was then recorded from the remaining CA1. Place cells were still present, suggesting that intrahippocampal circuits are not necessary for spatial signals to develop. The findings pointed to direct inputs from the entorhinal cortex as an alternative source of incoming spatial information to the hippocampus. Thus, in a subsequent study, we recorded directly from the entorhinal cortex, not in the deep ventral areas where cells had been recorded in previous studies, but in the dorsal parts that projected directly to the hippocampal recording locations used by O'Keefe and others (Fyhn et al. 2004). Electrodes were placed in the medial part of the entorhinal cortex. We found that many neurons in this area were as sharply modulated by position as place cells in the hippocampus. Entorhinal neurons had multiple firing fields with clear regions of silence between the fields. In a third study, we expanded the size of the recording environment 
to determine the spatial structure of the many firing fields (Hafting et al. 2005). The multiple firing fields of individual entorhinal neurons formed a regularly spaced triangular or hexagonal grid pattern, which repeated itself across the entire available space. We named these cells "grid cells." Grid cells were organized in a nontopographic manner, much like place cells. The firing fields of neighboring grid cells were no more similar than those of grid cells recorded at different brain locations. However, the scale of the grid increased from dorsal to ventral medial entorhinal cortex (Fyhn et al. 2004; Hafting et al. 2005), suggesting that the earliest recordings in the entorhinal cortex had missed the grid pattern because the period of the firing pattern was too large for repeated fields to be observed in conventionally sized recording boxes. The discovery of grid cells was followed by studies showing that these cells were part of a wider spatial network comprising other cell types as well, such as head direction-modulated cells (Sargolini et al. 2006) and cells that fire specifically along one or several borders of the local environment (border cells) (Savelli et al. 2008; Solstad et al. 2008). Head direction cells had previously been observed in a number of brain systems, from the dorsal tegmental nucleus in the brain stem to the pre- and parasubiculum in the parahippocampal cortex (Ranck 1985; Taube et al. 1990; Taube 2007). Border cells were described at the same time in the subiculum (Barry et al. 2006; Lever et al. 2009). Thus, by the end of the first decade of the new millennium, it was clear that place and grid cells were part of a diverse and entangled network of cell types with distinct functions in spatial representation.

How place cells are formed from the diversity of cell types remains to be determined. An obvious possibility is that place cells are generated by transformation of spatial input from grid cells. The presence of grid cells in the superficial layers of the entorhinal cortex, the main cortical input to the hippocampus, led investigators to propose that place fields form by linear combination of periodic firing fields from grid cells with a common central peak, but different grid spacing and orientation (O'Keefe and Burgess 2005; Fuhs and Touretzky 2006; McNaughton et al. 2006; Solstad et al. 2006). The suggestion was that, because the wavelength of the individual grid patterns is different, the patterns cancel each other except at the central peak, which becomes the place field of the receiving cell (Fig. 2).

Experimental observations have suggested that the mechanisms are more complex, however. If place cells were generated exclusively from grid cells, grid and place cells would be expected to appear simultaneously in developing animals or with a faster time course for grid cells than place cells. Recordings from rat pups suggest that this is not the case (Langston et al. 2010; Wills et al. 2010). When pups leave the nest for the first time at 2-2.5 weeks of age, sharp and confined firing fields are present in a large proportion of the hippocampal pyramidal-cell population. In contrast, grid cells show only weakly periodic fields at that age. Strong periodicity is not expressed until 3-4 weeks of age. The delayed maturation of the grid cells offers at least two interpretations. First, weak spatial inputs may be sufficient for place-cell formation. Sharply confined firing fields may be generated by local mechanisms in the hippocampal network, such as recurrent inhibition (de Almeida et al. 2009; Monaco and Abbott 2011), Hebbian plasticity (Rolls et al. 2006; Savelli and Knierim 2010), or active dendritic properties (Smith et al. 2013). Alternatively, place cells may be generated from other classes of spatially modulated cells, such as border cells, which have adult-like properties from the very first day of exploration outside the nest (Bjerknes et al. 2014). Retrograde labeling studies suggest that border cells have projections to the hippocampus that may be equally dense as those from grid cells, although the latter are more abundant (Zhang et al. 2013). A potential role for border cells in place-cell formation would be consistent with early models, suggesting that place cells arise by linear combination of inputs from cells with firing fields defined by their proximity to geometric boundaries (O'Keefe and Burgess 1996; Hartley et al. 2000). Recordings in the medial entorhinal cortex have, so far, identified such cells only near the boundaries of the environment (Solstad et al. 2008; Zhang et al. 2013; Bjerknes et al. 2014), suggesting that a contri- 
M.-B. Moser et al.
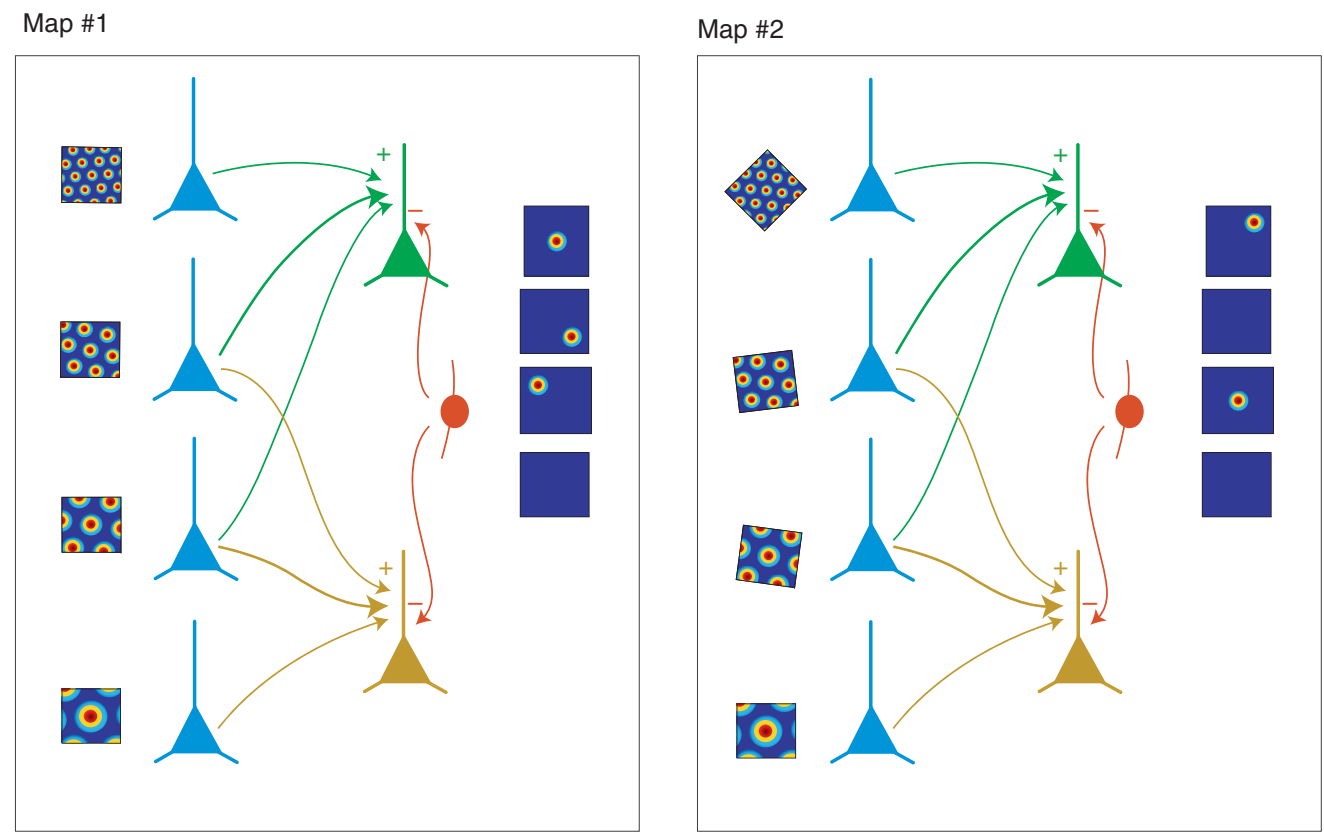

Figure 2. Schematic illustration of how periodic grid cells could be transformed to nonperiodic place cells by linear summation of output from grid cells with overlapping firing fields, but different spacing and orientation, and how differential responses among modules of grid cells might give rise to remapping in the hippocampus. (Left) Map 1, grid cells with different spacing converge to generate place cells in a subset of the hippocampal place-cell population. Each grid cell belongs to a different grid module. (Right) Map 2, differential realignment of each of the grid maps induces recruitment of a new subset of place cells. (From images in Solstad et al. 2006 and Fyhn et al. 2007; modified, with permission, from the authors and Nature Publishing Group (C) 2006 and 2007, respectively.)

bution by these cells may be limited to place cells with peripheral firing fields.

The exact function of different entorhinal cell types in place-cell formation remains to be determined, but it is not unlikely that individual place cells receive inputs from both grid and border cells, possibly with grid cells providing self-motion-based distance information and border cells providing position in relation to geometric boundaries (Bush et al. 2014; Zhang et al. 2014). The strongest input may originate from grid cells, which, in the superficial layers of the medial entorhinal cortex, are several times more abundant than border cells (Sargolini et al. 2006; Solstad et al. 2008; Boccara et al. 2010). Under most circumstances, the two classes of input are likely to be coherent and redundant. If one is absent, the other may often be sufficient to generate localized firing in the hippocampus.

\section{REMAPPING AND MEMORY}

One of the events that pointed to place cells as an expression of declarative memory was the discovery of remapping, or the fact that any place cell is part of not one, but many independent representations. In 1987, Bob Muller and John Kubie found that place cells can alter their firing patterns in response to minor changes in the experimental task, such as alterations in the shape of the recording enclosure (Fig. 3) (Muller and Kubie 1987; Bostock et al. 1991). Place cells may begin firing, stop firing, or change their firing location. The changes are expressed widely across the place-cell population, such that a new map is installed for each occasion. Remapping could also be induced by changes in motivational state or behavioral context (Markus et al. 1995; Frank et al. 2000; Wood et al. 2000; Moita et al. 2004). 

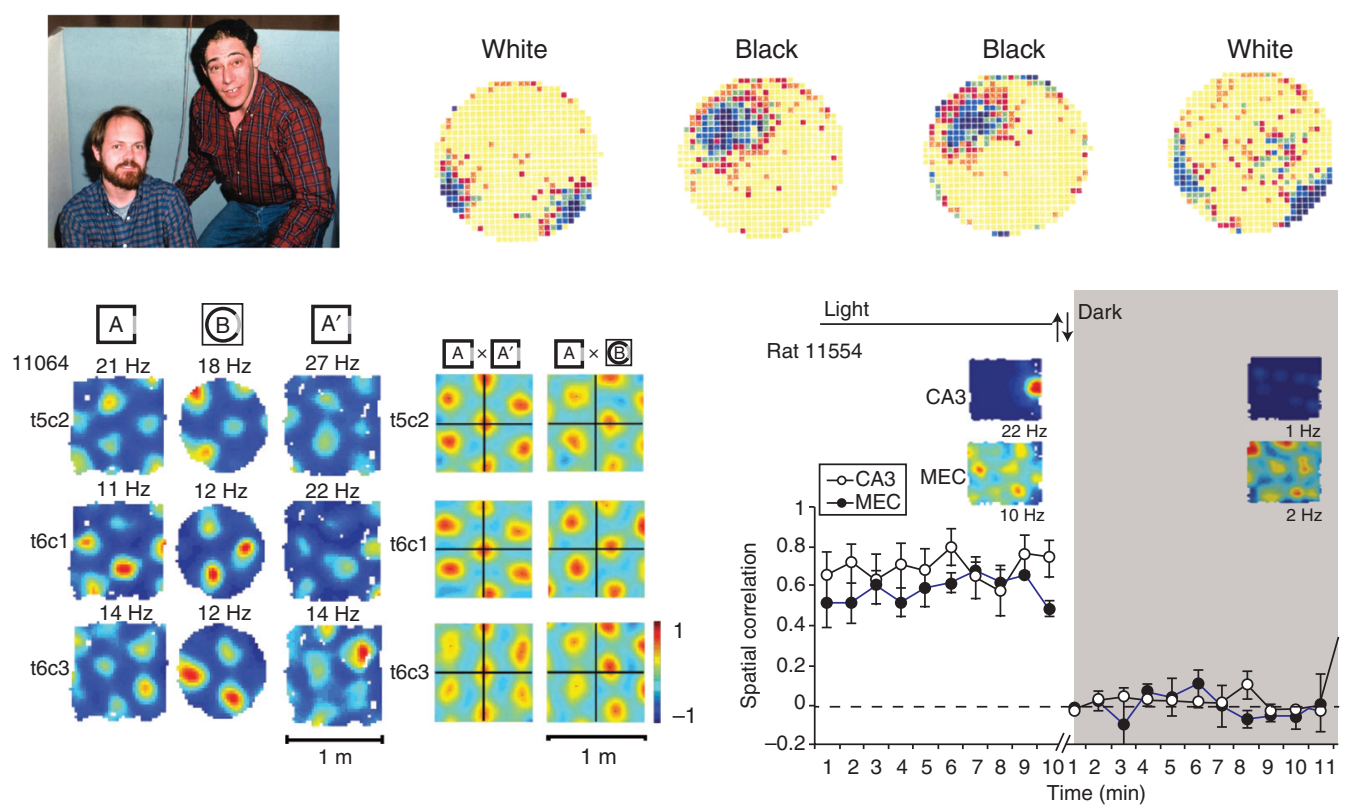

Figure 3. Remapping in place cells and grid cells. (Top left) John Kubie and Bob Muller in 1983. (Top right) Color-coded firing rate map for a hippocampal place cell from an early remapping experiment (purple, high rate; yellow, low rate). The cell fired at different locations in different versions of the recording cylinder, one with a black cue card and one with a white cue card. (Bottom left) Realignment of entorhinal grid cells under conditions that generate global remapping in the hippocampus. The rat was tested in boxes with square or circular surfaces. The left panel shows color-coded rate maps for three grid cells ( $\mathrm{t} 5 \mathrm{c} 2, \mathrm{t} 6 \mathrm{c} 1$, and $\mathrm{t} 6 \mathrm{c} 3$ ) (color coded as in Fig. 1). The right panel shows cross-correlation maps for pairs of rate maps (same grid cells as in the left panel; repeated trials in $A$ or one trial in $A$ and one trial in $B$ ). The cross-correlation maps are colorcoded, with red corresponding to high correlation and blue to low (negative) correlation. Note that the center of the cross-correlation map is shifted in the same direction and at a similar distance from the origin in all three grid cells, suggesting that all grid cells in an ensemble respond coherently to changes in the environment very much unlike the remapping that is observed in the hippocampus. (Bottom right) Response to a change in the environment (darkness) in a simultaneously recorded pair of grid and place cells. (Top left photo courteously provided by John Kubie; top right image is modified from data in Bostock et al. 1991; bottom image from Fyhn et al. 2007; reprinted, with permission, from the authors and Nature Publishing Group (C) 2007.)

The remapping experiments showed that place cells participate in multiple spatial maps. Different maps could be recruited not only in different environments, but also when animals are tested under different conditions in the same location (Markus et al. 1995; Leutgeb et al. 2005b). Maps for different conditions or places were often completely uncorrelated (global remapping) (Leutgeb et al. 2004; Fyhn et al. 2007), as if a pattern-separation process takes place when information enters the hippocampus from the surrounding cortex (Marr 1971; McNaughton and Morris 1987; Leutgeb et al. 2004,
2007). The discovery of remapping and the uncorrelated nature of place maps was important because it showed that place cells participate in multiple orthogonal representations, as expected if the hippocampus plays a role in accurate storage and retrieval of high-capacity declarative memory. The number of place maps stored in the hippocampus is not known, but if place maps are expressions of individual memories, that number should be very large. Remapping is, thus, a necessity if place cells express memories.

Do spatial inputs from medial entorhinal cortex contribute to remapping in the hippo- 
M.-B. Moser et al.

campus? The first clue to the underlying mechanism is that remapping is unique to the hippocampus. The orthogonal nature of place-cell maps is not shared by any of the known spatial cell types upstream of the hippocampus. In the hippocampus, and particularly in the CA3 subfield, different subsets of the place-cell population are active in different environments. The overlap between active subsets in two environments is not larger than expected by chance (Leutgeb et al. 2004). The apparent independence of the place-cell maps contrasts with the functional rigidity of the grid-cell population (Fig. 2). Changes in the environment, which lead to global remapping in the hippocampus, induce changes in the firing locations of simultaneously recorded grid cells, but these changes are always coherent among numbers of grid cells (Fyhn et al. 2007). Among grid cells with similar grid spacing, the firing locations of the grid cells shift in the $x y$ plane from one environment to the other, but the distance and direction of grid displacements are similar across the cell population. Similarly, internal coherence is observed in head direction and border cells. When animals are moved from one task to another, head direction cells in the presubiculum and anterior nuclei of the thalamus rotate coherently such that the magnitude of the difference in directional preference among any pair of head direction cells is retained from one condition to the next (Taube et al. 1990; Taube and Burton 1995; Yoganarasimha et al. 2006). A similar spatial coherence is seen among border cells (Solstad et al. 2008). Pairs of cells that fire along the same wall in one environment also fire along the same wall in another environment; cells that fire along opposite walls in one box fire along opposite walls in another box. Changes in orientation are coherent also across entorhinal cell types; if border fields switch to the opposite wall, this is accompanied by a 180-degree change in the orientation of head direction cells, as well as grid cells (Solstad et al. 2008). Taken together, these observations suggest that remapping is generated not in the entorhinal cortex, but in the hippocampus itself.

The findings do not rule out, however, that inputs from realigned or reoriented entorhinal cells give rise to remapping in the hippocampus. Two classes of explanations were put forward when we observed that remapping in the hippocampus is accompanied by coherent realignment in the grid-cell population (Fyhn et al. 2007). The first class assumed a continuous map of space in the medial entorhinal cortex. In this scenario, different portions of a universal entorhinal map would be activated in different environments. Different subsets of hippocampal cells would be activated from independent portions of the entorhinal map and global remapping would be seen in the hippocampus. The second class of explanation assumes that grid cells have a modular organization and that different modules of grid cells respond independently to changes in the environment. Place cells were thought to receive input from several modules. Differential realignment across modules would lead to different overlap of incoming grid signals in hippocampal target cells; the subset of hippocampal cells activated by entorhinal grid-cell inputs would be entirely dependent on the difference in realignment between different modules.

Subsequently, experimental studies have provided evidence for a modular organization of grid cells, consistent with the second explanation (Stensola et al. 2012). For many years, the low number of simultaneously recorded grid cells prevented a clear answer to the question of whether grid cells were modular or not, although early studies pointed in that direction (Barry et al. 2007). With a more than 10-fold increase in the number of grid cells from the same animal, it was possible to show that grid cells cluster into modules with distinct grid scale and grid orientation (Stensola et al. 2012). Four modules could be detected in most animals, but the number may be larger, considering that only a part of the medial entorhinal cortex was sampled. It was not only the properties of the grid pattern that differed between modules, however; they also responded independently to changes in the environment (Stensola et al. 2012). When the recording environment was compressed, changing it from a square to a rectangle, grid cells in the module with the smallest grid spacing maintained their firing locations, 
whereas cells in the larger modules rescaled completely and consistently, firing at shorter spatial wavelengths in the compressed direction, but maintaining wavelengths in the orthogonal unaltered direction. The apparent independence between grid modules contrasts with the strong coherence observed in earlier recordings from grid cells (Fyhn et al. 2007). The difference is likely to reflect the fact that the earlier recordings were all made from the same location and, probably, mostly from a single module.

The new data suggest that modules respond with different degrees of displacement and reorientation when animals move from one environment to another. Computational simulations have shown that independent realignment in four or fewer modules is sufficient to generate complete or global remapping in the hippocampus (Monaco and Abbott 2011). Independent responses among only a handful of grid modules may be sufficient to create an enormous diversity of firing patterns in the hippocampus because the number of displacements or phases that each module may take is large. The mechanism would be similar to that of a combination lock in which 10,000 combinations may be generated with only four modules of 10 possible values each (Rowland and Moser 2014), or that of an alphabet in which all words of a language can be generated by combining only 30 letters or less. The proposed mechanism is only a hypothesis, however. Whether hippocampal remapping actually requires independent realignment among grid modules remains to be determined. It should also be noted that a possible connection between grid modules and remapping does not rule out roles for other cell types, such as border cells, in inducing hippocampal remapping, although modular organization has not yet been observed in any of the other functional cell populations (Giocomo et al. 2014).

Finally, we would like to emphasize that, up to this point, we have mostly discussed the entorhinal-hippocampal space circuit as if interactions between cell types were constant over time. However, the connectivity of this network is dynamic (Buzsáki and Moser 2013). Whether entorhinal and hippocampal neurons influence each other depends strongly on the state of theta and gamma oscillations, which, during active awake behavior, predominates frequency spectra in both regions (Buzsáki et al. 1983; Bragin et al. 1995; Chrobak and Buzsáki 1998; Csicsvari et al. 2003; Colgin et al. 2009). Theta oscillations are generally coherent across most of the entorhinal-hippocampal network, but the coherence of beta and gamma oscillations is more local and fluctuates at subsecond timescales (Colgin et al. 2009; Igarashi et al. 2014). Such fluctuations may enable place cells to interact with different entorhinal subpopulations at different times. Coincidence of pre- and postsynaptic activity may be a prerequisite not only for synaptic strengthening of connections between entorhinal and hippocampal cell pairs (Singer 1993; Bi and Poo 1998), but also for patterncompletion processes during retrieval of already-stored information. Whether a place cell responds to inputs from grid or border cells may change with time, as may the influence of different modules of grid cells. Recordings from CA1 and lateral entorhinal cortex suggest that place cells also respond dynamically to nonspatial inputs, such as odors, with learned relationships to locations in the environment (Igarashi et al. 2014). Beta and gamma oscillations may enable place cells to respond temporarily to information about the content of locations in the spatial environment.

\section{CONCLUSION}

We have known for almost six decades that certain types of memory depend on the hippocampus and surrounding areas. The discovery of place cells showed that space is a critical element of the information that is stored and expressed by neurons in the hippocampus; however, it is, perhaps, with studies of place cells at the ensemble or population level and interventions that selectively change synaptic plasticity in specific brain circuits, that the mechanisms of memory processing have become accessible. Today, we know that hippocampal networks can rapidly store a multitude of uncorrelated representations, a property that any high-capacity episodic memory network must have. We know that 
M.-B. Moser et al.

place cells are only one element of a wider network for spatial mapping. Place cells coexist with grid, head direction, and border cells, all likely to interact with each other to yield a global representation of the animal's changing position, which may be used to guide the animal to particular locations in the environment. With a modular organization of grid cells, the network may be able to generate not only one map of the external environment, but thousands or millions. Whether and how these maps contribute to declarative memory remains to be determined, but the investigation of the hippocampal-entorhinal circuit is now at a stage in which the computational mechanisms underlying specific memory processes are fully addressable.

\section{REFERENCES}

Abbott LF, Blum KI. 1996. Functional significance of longterm potentiation for sequence learning and prediction. Cereb Cortex 6: 406-416.

Barnes CA, McNaughton BL, Mizumori SJ, Leonard BW, Lin LH. 1990. Comparison of spatial and temporal characteristics of neuronal activity in sequential stages of hippocampal processing. Prog Brain Res 83: 287-300.

Barry C, Lever C, Hayman R, Hartley T, Burton S, O’Keefe J, Jeffery K, Burgess N. 2006. The boundary vector corpcell model of place cell firing and spatial memory. Rev Neurosci 17: 71-97.

Barry C, Hayman R, Burgess N, Jeffery KJ. 2007. Experiencedependent rescaling of entorhinal grids. Nat Neurosci 10: 682-684.

Bi GQ, Poo MM. 1998. Synaptic modifications in cultured hippocampal neurons: Dependence on spike timing, synaptic strength, and postsynaptic cell type. J Neurosci 18: 10464-10472.

Bjerknes TL, Moser EI, Moser MB. 2014. Representation of geometric borders in the developing rat. Neuron 82: 7178.

Blum KI, Abbott LF. 1996. A model of spatial map formation in the hippocampus of the rat. Neural Comput 8: 85-93.

Boccara CN, Sargolini F, Thoresen VH, Solstad T, Witter MP Moser EI, Moser M-B. 2010. Grid cells in pre- and parasubiculum. Nat Neurosci 13: 987-994.

Bostock E, Muller RU, Kubie JL. 1991. Experience-dependent modifications of hippocampal place cell firing. Hippocampus 1: 193-205.

Bragin A, Jandó G, Nádasdy Z, Hetke J, Wise K, Buzsáki G. 1995. Gamma (40-100 Hz) oscillation in the hippocampus of the behaving rat. J Neurosci 15: 47-60.

Brun VH, Otnass MK, Molden S, Steffenach HA, Witter MP, Moser MB, Moser EI. 2002. Place cells and place recognition maintained by direct entorhinal-hippocampal circuitry. Science 296: 2243-2246.
Bush D, Barry C, Burgess N. 2014. What do grid cells contribute to place cell firing? Trends Neurosci 37: 136-145.

Buzsáki G. 1989. Two-stage model of memory trace formation: A role for "noisy" brain states. Neuroscience 31: $551-570$.

Buzsáki G, Moser EI. 2013. Memory, navigation and theta rhythm in the hippocampal-entorhinal system. $\mathrm{Nat} \mathrm{Neu-}$ rosci 16: 130-138.

Buzsáki G, Leung LW, Vanderwolf CH. 1983. Cellular bases of hippocampal EEG in the behaving rat. Brain Res 287: 139-171.

Chrobak JJ, Buzsáki G. 1998. Gamma oscillations in the entorhinal cortex of the freely behaving rat. J Neurosci 18: $388-398$.

Chun MM, Turk-Browne NB. 2007. Interactions between attention and memory. Curr Opin Neurobiol 17: 177-184.

Cohen NJ, Squire LR. 1980. Preserved learning and retention of pattern analyzing skill in amnesia: Dissociation of knowing how and knowing that. Science 210: 207-209.

Colgin LL, Denninger T, Fyhn M, Hafting T, Bonnevie T, Jensen O, Moser MB, Moser EI. 2009. Frequency of gamma oscillations routes flow of information in the hippocampus. Nature 462: 353-357.

Corkin S. 2002. What's new with the amnesic patient H.M.? Nature Rev Neurosci 3: 153-160.

Csicsvari J, Jamieson B, Wise KD, Buzsáki G. 2003. Mechanisms of gamma oscillations in the hippocampus of the behaving rat. Neuron 37: 311-322.

de Almeida L, Idiart M, Lisman JE. 2009. The input-output transformation of the hippocampal granule cells: From grid cells to place fields. J Neurosci 29: 7504-7512.

Diba K, Buzsaki G. 2007. Forward and reverse hippocampal place-cell sequences during ripples. Nat Neurosci 10: 1241-1242.

Dragoi G, Tonegawa S. 2011. Preplay of future place cell sequences by hippocampal cellular assemblies. Nature 469: 397-401.

Dragoi G, Tonegawa S. 2013. Distinct preplay of multiple novel spatial experiences in the rat. Proc Natl Acad Sci 110: $9100-9105$.

Ebbinghaus H. 1885. Über das Gedächtnis Untersuchungen zur Experimentellen Psychologie [Memory: A contribution to experimental psychology]. von Duncker and Humber, Leipzig, Germany.

Ego-Stengel V, Wilson MA. 2010. Disruption of rippleassociated hippocampal activity during rest impairs spatial learning in the rat. Hippocampus 20: 1-10.

Eichenbaum H, Kuperstein M, Fagan A, Nagode J. 1987. Cue-sampling and goal-approach correlates of hippocampal unit activity in rats performing an odor-discrimination task. J Neurosci 7: 716-732.

Ekstrom AD, Meltzer J, McNaughton BL, Barnes CA. 2001 NMDA receptor antagonism blocks experience-dependent expansion of hippocampal "place fields." Neuron 31: 631-638.

Ferbinteanu J, Shapiro ML. 2003. Prospective and retrospective memory coding in the hippocampus. Neuron 40: 1227-1239. 
Foster DJ, Wilson MA. 2006. Reverse replay of behavioural sequences in hippocampal place cells during the awake state. Nature 440: 680-683.

Frank LM, Brown EN, Wilson M. 2000. Trajectory encoding in the hippocampus and entorhinal cortex. Neuron 27: 169-178.

Frank LM, Stanley GB, Brown EN. 2004. Hippocampal plasticity across multiple days of exposure to novel environments. J Neurosci 24: 7681-7689.

Frankland PW, O'Brien C, Ohno M, Kirkwood A, Silva AJ. 2001. $\alpha$-CaMKII-dependent plasticity in the cortex is required for permanent memory. Nature 411: 309-313.

Fuhs MC, Touretzky DS. 2006. A spin glass model of path integration in rat medial entorhinal cortex. J Neurosci 26: $4266-4276$.

Fyhn M, Molden S, Witter MP, Moser EI, Moser M-B. 2004. Spatial representation in the entorhinal cortex. Science 305: $1258-1264$.

Fyhn M, Hafting T, Treves A, Moser M-B, Moser EI. 2007. Hippocampal remapping and grid realignment in entorhinal cortex. Nature 446: 190-194.

Gelbard-Sagiv H, Mukamel R, Harel M, Malach R, Fried I. 2008. Internally generated reactivation of single neurons in human hippocampus during free recall. Science 322: 96-101.

Giocomo LM, Stensola T, Bonnevie T, Van Cauter T, Moser M-B, Moser EI. 2014. Topography of head direction cells in medial entorhinal cortex. Curr Biol 24: 252-262.

Girardeau G, Benchenane K, Wiener SI, Buzsaki G, Zugaro MB. 2009. Selective suppression of hippocampal ripples impairs spatial memory. Nat Neurosci 12: 1222-1223.

Gupta AS, van der Meer MA, Touretzky DS, Redish AD. 2010. Hippocampal replay is not a simple function of experience. Neuron 65: 695-705.

Hafting T, Fyhn M, Molden S, Moser M-B, Moser EI. 2005. Microstructure of a spatial map in the entorhinal cortex. Nature 436: 801-806.

Hampson RE, Heyser CJ, Deadwyler SA. 1993. Hippocampal cell firing correlates of delayed-match-to-sample performance in the rat. Behav Neurosci 107: 715-739.

Hartley T, Burgess N, Lever C, Cacucci F, O'Keefe J. 2000. Modeling place fields in terms of the cortical inputs to the hippocampus. Hippocampus 10: 369-379.

Hassabis D, Kumaran D, Maguire EA. 2007. Using imagination to understand the neural basis of episodic memory. $J$ Neurosci 27: 14365-14374.

Hebb DO. 1949. The organization of behavior. Wiley, New York.

Hill AJ. 1978. First occurrence of hippocampal spatial firing in a new environment. Exp Neurol 62: 282-297.

Hoffman KL, McNaughton BL. 2002. Coordinated reactivation of distributed memory traces in primate neocortex. Science 297: 2070-2073.

Igarashi KM, Lu L, Colgin LL, Moser M-B, Moser EI. 2014. Coordination of entorhinal-hippocampal ensemble activity during associative learning. Nature 510: 143-147.

Jung MW, Wiener SI, McNaughton BL. 1994. Comparison of spatial firing characteristics of units in dorsal and ventral hippocampus of the rat. J Neurosci 14: 7347-7356.
Kandel ER, Schwartz JH. 1982. Molecular biology of learning: Modulation of transmitter release. Science 218: 433 443.

Karlsson MP, Frank LM. 2009. Awake replay of remote experiences in the hippocampus. Nat Neurosci 12: 913918.

Kentros C, Hargreaves E, Hawkins RD, Kandel ER, Shapiro M, Muller RV. 1998. Abolition of long-term stability of new hippocampal place cell maps by NMDA receptor blockade. Science 280: 2121-2126.

Kentros CG, Agnihotri NT, Streater S, Hawkins RD, Kandel ER. 2004. Increased attention to spatial context increases both place field stability and spatial memory. Neuron 42: 283-295.

Kjelstrup KB, Solstad T, Brun VH, Hafting T, Leutgeb S, Witter MP, Moser EI, Moser M-B. 2008. Finite scales of spatial representation in the hippocampus. Science 321: $140-143$.

Langston RF, Ainge JA, Couey JJ, Canto CB, Bjerknes TL, Witter MP, Moser EI, Moser M-B. 2010. Development of the spatial representation system in the rat. Science 328: $1576-1580$.

Lashley KS. 1929. Brain mechanisms and intelligence: A qualitative study of injuries to the brain. University of Chicago Press, Chicago.

Lashley KS. 1950. In search of the engram. In Symposium of the society for experimental biology, Vol. 4. Cambridge University Press, New York.

Leutgeb S, Leutgeb JK, Treves A, Moser M-B, Moser EI. 2004. Distinct ensemble codes in hippocampal areas CA3 and CA1. Science 305: 1295-1298.

Leutgeb JK, Leutgeb S, Treves A, Meyer R, Barnes CA, McNaughton BL, Moser M-B, Moser EI. 2005a. Progressive transformation of hippocampal neuronal representations in "morphed" environments. Neuron 48: 345-358.

Leutgeb S, Leutgeb JK, Barnes CA, Moser EI, McNaughton BL, Moser M-B. 2005b. Independent codes for spatial and episodic memory in hippocampal neuronal ensembles. Science 309: 619-623.

Leutgeb S, Leutgeb JK, Moser EI, Moser MB. 2006. Fast rate coding in hippocampal CA3 cell ensembles. Hippocampus 16: 765-774.

Leutgeb JK, Leutgeb S, Moser MB, Moser EI. 2007. Pattern separation in the dentate gyrus and CA3 of the hippocampus. Science 315: 961-966.

Lever C, Burton S, Jeewajee A, O’Keefe J, Burgess N. 2009. Boundary vector cells in the subiculum of the hippocampal formation. J Neurosci 29: 9771-9777.

Markus EJ, Qin YL, Leonard B, Skaggs WE, McNaughton BL, Barnes CA. 1995. Interactions between location and task affect the spatial and directional firing of hippocampal neurons. J Neurosci 15: 7079-7094.

Marr D. 1971. Simple memory: A theory for archicortex. Philos Trans R Soc Lond B Biol Sci 262: 23-81.

McClelland JL, McNaughton BL, O'Reilly RC. 1995. Why there are complementary learning systems in the hippocampus and neocortex: Insights from the successes and failures of connectionist models of learning and memory. Psychol Rev 102: 419-457.

McHugh TJ, Blum KI, Tsien JZ, Tonegawa S, Wilson MA. 1996. Impaired hippocampal representation of space in 
M.-B. Moser et al.

CA1-specific NMDAR1 knockout mice. Cell 87: 13391349.

McNaughton BL, Battaglia FP, Jensen O, Moser EI, Moser M-B. 2006. Path integration and the neural basis of the "cognitive map." Nature Rev Neurosci 7: 663-678.

Mehta MR, Barnes CA, McNaughton BL. 1997. Experiencedependent, asymmetric expansion of hippocampal place fields. Proc Natl Acad Sci 94: 8918-8921.

Mehta MR, Quirk MC, Wilson MA. 2000. Experience-dependent asymmetric shape of hippocampal receptive fields. Neuron 25: 707-715.

Miller JF, Neufang M, Solway A, Brandt A, Trippel M, Mader I, Hefft S, Merkow M, Polyn SM, Jacobs J, et al. 2013 Neural activity in human hippocampal formation reveals the spatial context of retrieved memories. Science 342: 1111-1114.

Milner B, Corkin S, Teuber HL. 1968. Further analysis of the hippocampal amnesic syndrome: 14-year follow-up study of H.M. Neuropsychologia 6: 215-234.

Mishkin M. 1978. Memory in monkeys severely impaired by combined but not by separate removal of amygdala and hippocampus. Nature 273: 297-298.

Moita MA, Rosis S, Zhou Y, LeDoux JE, Blair HT. 2004 Putting fear in its place: Remapping of hippocampal place cells during fear conditioning. I Neurosci 24: 7015-7023.

Monaco JD, Abbott LF. 2011. Modular realignment of entorhinal grid cell activity as a basis for hippocampal remapping. J Neurosci 31: 9414-9425.

Monaco JD, Rao G, Roth ED, Knierim JJ. 2014. Attentive scanning behavior drives one-trial potentiation of hippocampal place fields. Nat Neurosci 17: 725-731.

Moser EI, Kropff E, Moser M-B. 2008. Place cells, grid cells, and the brain's spatial representation system. Annu Rev Neurosci 31: 69-89.

Muller RU, Kubie JL. 1987. The effects of changes in the environment on the spatial firing of hippocampal complex-spike cells. J Neurosci 7: 1951-1968.

Muzzio IA, Levita L, Kulkarni J, Monaco J, Kentros C, Stead M, Abbott LF, Kandel ER. 2009. Attention enhances the retrieval and stability of visuospatial and olfactory representations in the dorsal hippocampus. PLoS Biol 7: e1000140.

O'Keefe J. 1976. Place units in the hippocampus of the freely moving rat. Exp Neurol 51: 78-109.

O'Keefe J, Burgess N. 1996. Geometric determinants of the place fields of hippocampal neurons. Nature 381: 425428.

O'Keefe J, Burgess N. 2005. Dual phase and rate coding in hippocampal place cells: Theoretical significance and relationship to entorhinal grid cells. Hippocampus 15: 853866.

O'Keefe J, Dostrovsky J. 1971. The hippocampus as a spatial map. Preliminary evidence from unit activity in the freely-moving rat. Brain Res 34: 171-175.

O'Keefe J, Nadel L. 1978. The hippocampus as a cognitive map. Clarendon, Oxford.

O'Keefe J, Speakman A. 1987. Single unit activity in the rat hippocampus during a spatial memory task. Exp Brain Res 68: 1-27.
O’Neill J, Senior T, Csicsvari J. 2006. Place-selective firing of CA1 pyramidal cells during sharp wave/ripple network patterns in exploratory behavior. Neuron 49: 143-155.

Pavlides C, Winson J. 1989. Influences of hippocampal place cell firing in the awake state on the activity of these cells during subsequent sleep episodes. J Neurosci 9: 29072918.

Pfeiffer BE, Foster DJ. 2013. Hippocampal place-cell sequences depict future paths to remembered goals. Nature 497: 74-79.

Quirk GJ, Muller RU, Kubie JL, Ranck JB Jr. 1992. The positional firing properties of medial entorhinal neurons: Description and comparison with hippocampal place cells. J Neurosci 12: 1945-1963.

Ranck JB Jr. 1973. Studies on single neurons in dorsal hippocampal formation and septum in unrestrained rats: I. Behavioral correlates and firing repertoires. Exp Neurol 41: 461-531.

Ranck JB. 1985. Head direction cells in the deep cell layer of dorsal presubiculum in freely moving rats. In Electrical activity of the archicortex (ed. Buzsáki G, Vanderwolf $\mathrm{CH})$, pp. 217-220. Akademiai Kiado, Budapest.

Rolls ET, Stringer SM, Elliot T. 2006. Entorhinal cortex grid cells can map to hippocampal place cells by competitive learning. Network 17: 447-465.

Rotenberg A, Mayford M, Hawkins RD, Kandel ER, Muller RU. 1996. Mice expressing activated CaMKII lack low frequency LTP and do not form stable place cells in the CA1 region of the hippocampus. Cell 87: 1351-1361.

Rowland DC, Moser M-B. 2014. From cortical modules to memories. Curr Opin Neurobiol 24C: 22-27.

Samsonovich A, McNaughton BL. 1997. Path integration and cognitive mapping in a continuous attractor neural network model. J Neurosci 17: 5900-5920.

Sargolini F, Fyhn M, Hafting T, McNaughton BL, Witter MP, Moser M-B, Moser EI. 2006. Conjunctive representation of position, direction and velocity in entorhinal cortex. Science 312: 754-758.

Savelli F, Knierim JJ. 2010. Hebbian analysis of the transformation of medial entorhinal grid-cell inputs to hippocampal place fields. J Neurophysiol 103: 3167-3183.

Savelli F, Yoganarasimha D, Knierim JJ. 2008. Influence of boundary removal on the spatial representations of the medial entorhinal cortex. Hippocampus 18: 1270-1282.

Scoville WB, Milner B. 1957. Loss of recent memory after bilateral hippocampal lesions. J Neurol Neurosurg Psychiatry 20: 11-21.

Singer W. 1993. Synchronization of cortical activity and its putative role in information processing and learning. Annu Rev Physiol 55: 349-374.

Smith SL, Smith IT, Branco T, Häusser M. 2013. Dendritic spikes enhance stimulus selectivity in cortical neurons in vivo. Nature 503: 115-120.

Solstad T, Moser EI, Einevoll GT. 2006. From grid cells to place cells: A mathematical model. Hippocampus 16: 1026-1031.

Solstad T, Boccara CN, Kropff E, Moser M-B, Moser EI. 2008. Representation of geometric borders in the entorhinal cortex. Science 322: 1865-1868. 
Place Cells, Grid Cells, and Memory

Squire LR. 1992. Memory and the hippocampus: A synthesis from findings with rats, monkeys, and humans. Psychol Rev 99: 195-231.

Squire LR, Alvarez P. 1995. Retrograde amnesia and memory consolidation: A neurobiological perspective. Curr Opin Neurobiol 5: 169-177.

Stensola H, Stensola T, Solstad T, Frøland K, Moser M-B, Moser EI. 2012. The entorhinal map is discretized. $\mathrm{Na}$ ture 492: 72-78.

Suddendorf T, Corballis MC. 2007. The evolution of foresight: What is mental time travel, and is it unique to humans? Behav Brain Sci 30: 299-313.

Taube JS. 2007. The head direction signal: Origins and sensory-motor integration. Annu Rev Neurosci 30: 181207.

Taube JS, Burton HL. 1995. Head direction cell activity monitored in a novel environment and during a cue conflict situation. J Neurophysiol 74: 1953-1971.

Taube JS, Muller RU, Ranck JB Jr. 1990. Head-direction cells recorded from the postsubiculum in freely moving rats: I. Description and quantitative analysis. J Neurosci 10: 420-435.

Tolman EC. 1948. Cognitive maps in rats and men. Psychol Rev 55: 189-208.

Watrous AJ, Tandon N, Conner CR, Pieters T, Ekstrom AD. 2013. Frequency-specific network connectivity increases underlie accurate spatiotemporal memory retrieval. Nat Neurosci 16: 349-356.

Wills TJ, Cacucci F, Burgess N, O’Keefe J. 2010. Development of the hippocampal cognitive map in preweanling rats. Science 328: $1573-1576$.
Wilson MA, McNaughton BL. 1993. Dynamics of the hippocampal ensemble code for space. Science 261: 10551058.

Wilson MA, McNaughton BL. 1994. Reactivation of hippocampal ensemble memories during sleep. Science 265: 676-679.

Wood ER, Dudchenko PA, Eichenbaum H. 1999. The global record of memory in hippocampal neuronal activity. $\mathrm{Na}$ ture 397: 613-616.

Wood ER, Dudchenko PA, Robitsek RJ, Eichenbaum H. 2000. Hippocampal neurons encode information about different types of memory episodes occurring in the same location. Neuron 27: 623-633.

Yoganarasimha D, Yu X, Knierim JJ. 2006. Head direction cell representations maintain internal coherence during conflicting proximal and distal cue rotations: Comparison with hippocampal place cells. J Neurosci 26: 622-631.

Young BJ, Fox GD, Eichenbaum H. 1994. Correlates of hippocampal complex-spike cell activity in rats performing a nonspatial radial maze task. J Neurosci 14: 6553-6563.

Zhang SJ, Ye J, Miao CL, Tsao A, Cerniauskas I, Ledergerber D, Moser M-B, Moser EI. 2013. Optogenetic dissection of entorhinal-hippocampal functional connectivity. Science 340: 1232627.

Zhang S-J, Ye J, Couey JJ, Witter MP, Moser EI, Moser M-B. 2014. Functional connectivity of the entorhinal-hippocampal space circuit. Philos Trans R Soc Lond B Biol Sci 369: 20120516.

Zola-Morgan S, Squire LR, Amaral DG. 1986. Human amnesia and the medial temporal region: Enduring memory impairment following a bilateral lesion limited to field CA1 of the hippocampus. J Neurosci 6: 2950-2967. 


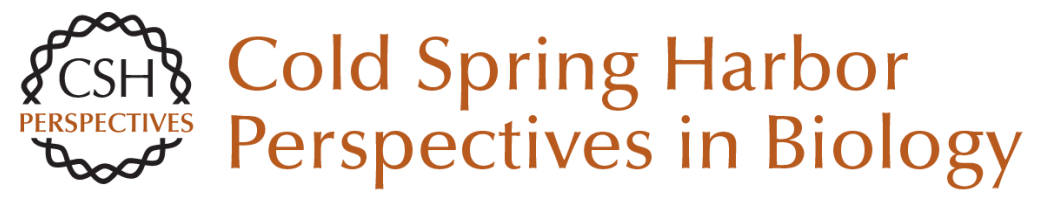

\section{Place Cells, Grid Cells, and Memory}

May-Britt Moser, David C. Rowland and Edvard I. Moser

Cold Spring Harb Perspect Biol 2015; doi: 10.1101/cshperspect.a021808

Subject Collection Learning and Memory

Large-Scale Fluorescence Calcium-Imaging Methods for Studies of Long-Term Memory in Behaving Mammals

Pablo Jercog, Thomas Rogerson and Mark J. Schnitzer

Exploring Memory Representations with

Activity-Based Genetics

Mark Mayford and Leon Reijmers

The Origins and Organization of Vertebrate

Pavlovian Conditioning Michael S. Fanselow and Kate M. Wassum

The Corticohippocampal Circuit, Synaptic

Plasticity, and Memory

Jayeeta Basu and Steven A. Siegelbaum

Motor Learning and the Cerebellum Chris I. De Zeeuw and Michiel M. Ten Brinke

The Striatum: Where Skills and Habits Meet Ann M. Graybiel and Scott T. Grafton

Molecular Genetic Strategies in the Study of Corticohippocampal Circuits

Christopher C. Angelakos and Ted Abel

Nonassociative Learning in Invertebrates John H. Byrne and Robert D. Hawkins
The Role of Functional Prion-Like Proteins in the Persistence of Memory

Kausik Si and Eric R. Kandel

Working Memory: Maintenance, Updating, and the Realization of Intentions

Lars Nyberg and Johan Eriksson

Memory Retrieval in Mice and Men

Aya Ben-Yakov, Yadin Dudai and Mark R. Mayford

Reconsolidation and the Dynamic Nature of

Memory

Karim Nader

Memory Consolidation

Larry R. Squire, Lisa Genzel, John T. Wixted, et al.

Structural Components of Synaptic Plasticity and Memory Consolidation

Craig H. Bailey, Eric R. Kandel and Kristen M.

Harris

Associative Learning in Invertebrates

Robert D. Hawkins and John H. Byrne

The Regulation of Transcription in Memory

Consolidation

Cristina M. Alberini and Eric R. Kandel

For additional articles in this collection, see http://cshperspectives.cshlp.org/cgi/collection/

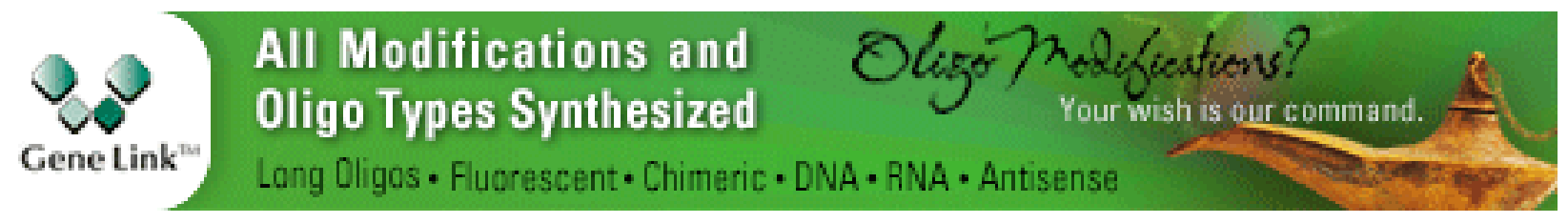

Copyright @ 2015 Cold Spring Harbor Laboratory Press; all rights reserved 